\title{
PENGARUH DOSIS PUUK KANDANG SAPI TERHADAP PERBAIKAN BEBERAPA SIFAT FISIK, KIMIA DAN BIOLOGI TANAH PADA KONDISI JENUH AIR DAN KAPSITAS LAPANG
}

\author{
Julio Correia
}

\begin{abstract}
Soils are the main media for growth of crops, the low yield of crops is always related to soil physical, chemical and biological soil conditions. Cattle manure is an organic fertilizer known well before chemical fertilizer. Many researches on the use of cattle manure to ameliorate physical, chemical and biological soil properties have been conducted, but the optimum rates of cattle manures especially on sandy soil have never been found. This fact may be caused by leaching of organic materials and nutrients to deeper soil layer unreachable by roots.

An experiment was conducted in a plastic house using sandy soils from the district of Kubu, Karangsem regency, with the objectives of studyng the effects of rates of cattle manure on physical, chemical and biological properties f soils and the effects of inundated and water field capacity of soils on leaching of nutrients in the soils. Experiment was conducted from June until August 2010. The design used was a split-plot design consisted of four rates of cattle manure $\left(0,10,20\right.$ and $\left.30 \mathrm{t} \mathrm{ha}^{-1}\right)$ as main plots and two water status of soils (inundated and water capacity) as subplots, with three replications.

The results of the experiment indicated that cattle manure is able to ameliorate some of the soil physical properties as bulk densities $\left(\mathrm{g} \mathrm{cm}^{-3}\right)$, soil water status $(\%)$, soil permeability $\left(\mathrm{cm} \mathrm{hour}^{-1}\right)$ and total soil pores $(\%)$, and increased soil $\mathrm{pH}, \mathrm{C}$-organik content (\%), C/N ratio, NPK and biological properties of soils of low nutrients status of sandy loam brown regosol soils derived from vulcan intermedier. The results of the experiment also indicated the occurrence of leaching of organic materials and NPK nutrients to $20-40 \mathrm{~cm}$ layer. Based on the experiment results it is to suggested to the farmers that the use of cattle manure should be combined with synthetic chemical fertilizer in several applications during growth periods, but this required further researches.
\end{abstract}

Key words: Cattle manures, water condition, amelioration of physical, chemical and biological properties of soils.

\section{Pendahuluan}

Pupuk Organik merupakan pupuk yang dapat bermanfaat bagi perbaikan sifat fisik, kimia dan biologi tanah. Salah satu jenis pupuk organik yang dapat dimanfaatkan adalah pupuk kandang sapi.

Pupuk kandang sapi yang telah dianalisis oleh Balai Penellitian Tanah Bogor memiliki pH 7,0, kadar air 34- 
Julio: Pengaruh dosis puuk kandang sapi terhadap perbaikan beberapa sifat fisik, kimia dan biologi tanah pada kondisi jenuh air dan kapsitas lapang

37\%, C-Organik 10,95\%, nitorgen 0,84 $\%, \mathrm{C} / \mathrm{N}$ ratio 14 , fosfor $\left(\mathrm{P}_{2} \mathrm{O}_{5}\right) 0,44 \%$ dan Kalium 0,28 \%. Pupuk kandang sapi digunakan pada tanah-tanah yang kandungan haranya sangat rendah dan untuk tanah dengan struktur padat diperlukan dosis yang tinggi $\left(20-30 \mathrm{tha}^{-1}\right)$ (Marsono dan Sigit, 2000).

Pemberian pupuk bagi tanamanm sering tidak dapat diserap oleh tanaman. Hal ini dapat terjadi karena unsur hara dari pupuk dapat tercuci atau terhanyut oleh air hujan. Hal ini dapat terjadi pada tanah pasir berlempung dengan $\mathrm{C}$ Organik sangat rendah sehingga kemampuan tanah memegang air dan unsur hara sangat rendah. Kondisi ini terjadi juga pada lahan kering di Kecamatan Kubu, Kabupaten Karangasem. Tanah ini termasuk Regosol Coklat dengan bahan induk Vulkan Intermedier yang berasal dari abu vukan letusan gunung merapi. Secara kimiawi tanah yang dipakai dalam penelitian ini mempunyai $\mathrm{pH} 7,0, \mathrm{C}$-Organik $0,55 \%, \mathrm{~N}$ total $0,06 \%$, P-tersedia $22 \mathrm{ppm}, \mathrm{K}$ tersedia 166,7 ppm dan $\mathrm{C} / \mathrm{N}$ ratio 9. Berdasarkan hasil analisis sifat fisik tanah berat, volume tanah $1,5 \mathrm{~g} \mathrm{~cm}^{-3}$, kadar air tanah 8,07-13,73 \% dan permeabilitas tanah > $25 \mathrm{~cm} \mathrm{jam}^{-1}$ tergolong cepat hingga sangat cepat.

Penelitian tentang faktor penyebab belum tercapainya dari pemberian pupuk kandang sapi terhadap pertumbuhan dan hasil tanaman sangat terbatas sehingga perlu dilakukan penelitian tentang masalah tersebut untuk membuktikan apakah memang terjadi pencucian atau pelindian hara dari pupuk kandang sapi oleh air hujan. Pelindian hara tersebut dapat diketahui dengan meneliti status hara di lapisan tanah di bawah zona perakaran (kedalaman di bawah $20 \mathrm{~cm}$ ) pada kondisi tanah jenuh air dibandngkan kondisi air pada kapasitas lapang. Untuk mengetahui mekanismenya lebih detail maka perlu dilakukan percobaan pot dengan mensimulasikan kedalamn tanah dari permukaan $40 \mathrm{~cm}$ di bawahnya. Oleh karena itu perlu dilakukan penelitian beberapa dosis pupuk kandang sapi pada dua kondisi air tanah kondisi jenuh dan tidak jenuh (kapasitas lapang) dengan melakukan pengamatan sifat fisik, kimia dan biologi tanah secara periodik yaitu, sebelum pemberian pupuk kandang sapi, 15 hsp, 30 hsp, 45 hsp dan 60 hsp, sehingga akan diketa Kurnia dkk, 2006hui perubahan fisik, kimia dan 
Julio: Pengaruh dosis puuk kandang sapi terhadap perbaikan beberapa sifat fisik, kimia dan biologi tanah pada kondisi jenuh air dan kapsitas lapang

biologi yang terjadi dalam tanah setelah pemberian pupuk kandang sapi.

\section{Metode Penelitian}

\section{Rancangan Percobaan}

Penelitian ini adalah percobaan pot. Rancangan percobaan yang digunakan adalah rancangan petak terpisah (split plot design) dengan tiga ulangan.

Sebagai petak utama adalah dosis pupuk kandang sapi yaitu ${ }^{-1} \mathrm{P} 0$ : $0 \mathrm{t} \mathrm{ha}^{-1}$, P1: $10 \mathrm{t} \mathrm{ha}^{-1}, \mathrm{P} 2: 20 \mathrm{t} \mathrm{ha}^{-1}$ dan P3: $30 \mathrm{t} \mathrm{ha}^{-}$ 1 . Sebagai anak petak adalah kandungan air tanah yaitu, Ka1: kandungan 57\% (kondisi air jenuh), Ka2: kandungan air 27\% (kondisi tidak jenuh air).

Percobaan terdiri atas $4 \times 2 \times 3=24$ pot. Susunan pot percobaan dengan rancangan petak. Semua pot didestruksi (destruksi sampling) sehingga setiap perlakuan diwakili 1 pot. Jumlah pot percobaan dalam penelitian ini adalah $24 \times 4=96$ pot.

\section{Lokasi dan Waktu Penelitian}

Penelitian ini dilakukan di Perumahan Sepa Guntur, Denpasar Barat, pada bulan Juni hingga Agustus 2010.

\section{Variabel Pengamatan}

Variabel yang diamati dalam peneltian ini meliputi beberapa sifat fisik tanah (volume tanah, total ruang pori tanah, kadar air tanah dan permeabilitas) dan sifat kimia tanah $(\mathrm{pH}$ tanah, Corganik, $\mathrm{C} / \mathrm{N}$ ratio, $\mathrm{N}, \mathrm{P}, \mathrm{K}$ ) dan biologi tanah.

\section{Alat dan Bahan}

Alat yang digunakan dalam penelitiatan ini adalah polybag, cangkul, sekop, pisau, ember, saringan tanah, kantong plastik, karung, meteran, klinometer, kamera digital, buku catatan, spidol, timbangan, ring sampel, sendok kecil dan palu. Bahan yang digunakan dalam penelitian adalah tanah, pupuk kandang sapi dan air.

\section{Analisis Data}

Data dianalisis secara statistik dengan menggunakan analisis sidik ragam dan pengaruh interaksi yang berpengaruh nyata dilanjutkan dengan uji Duncan 5\%. Perlakuan tunggal yang berpengaru nyata, maka analisis dilanjutkan dengan uji Beda Nyata Terkecil (BNT) 5\%.

\section{Hasil dan Pembahasan}

\section{Total ruang pori}

Dosis pupuk kandang sapi mampu meningkatkan total ruang pori tanah pada semua lapisan $(0-20 \mathrm{~cm}$ dan $20-40 \mathrm{~cm})$ kondisi jenuh air dan kapasitas lapang. 
Julio: Pengaruh dosis puuk kandang sapi terhadap perbaikan beberapa sifat fisik, kimia dan biologi tanah pada kondisi jenuh air dan kapsitas lapang

Hal ini menunjukan bahwa pupuk kandang sapi mampu membentuk koloid tanah sehingga dapat meningkatkan total ruang pori tanah pasir seperti tanah contoh dalam percobaan ini.

\section{Berat volume tanah}

Pengaruh interaksi pemakaian dosis pupuk kandang sapi dan kadar air dapat menurunkan berat volume tanah secara berangsur dari 10, 20 dan $30 \mathrm{t} \mathrm{ha}^{-1}$ pada lapisan 0-20 cm, dan 20-40 $\mathrm{cm}$ pada kondisi kandungan jenuh air dan kapasitas lapang 15 hsp, 45 hsp dan 60 hsp.

Hasil percobaan menunjukan bahwa berat volume tanah tanpa pemakaian pupuk kandang sapi adalah 1,50-1,51 gr $\mathrm{cm}^{-3}$. Hasil ini sesuai dengan penemuan Danahue et al (1977) yang menemukan bahwa pada tanah-tanah berpasir untuk pertumbuhan tanaman yang baik, berat volume tanah harus lebih rendah dari 1,6 gr $\mathrm{cm}^{-3}$. Puja dkk. (1990), menyatakan bahwa berat volume tanah pertanian umumnya berkisar antara $0,8 \mathrm{gr} \mathrm{\textrm {cm } ^ { - 3 }}$ sampai $1,8 \mathrm{gr} \mathrm{cm}^{-3}$ (Kurnia dkk, 2006).

\section{Kandungan air tanah}

Pengaruh interaksi pemakaian dosis pupuk kandang sapi dan kadar air tanah dapat meningkatkan daya pegang air tanah pada tanah yang bertekstur pasir. Berdasarkan hasil data yang diperoleh ditemukan bahwa kadar air tanah meningkat sesuai dengan dosis pupuk yang diberikan. Dosis pupuk kandang sapi terbukti dapat memperbaiki sifat fisik tanah terutama kemampuan daya pegang air pada tanah yang bertekstur pasir lempung yang sangat rentan dengan pencucian (perlindian). Tanah asal daerah Kubu yang didominasi pasir dari abu vulkan gunung berapi sangat peka terhadap erosi. Maka dengan pemberian pupuk kandang sapi diharapkan akan mampu meningkatkan daya pegang air sehingga meningkatkan proses pertumbuhan tanaman di daerah tersebut.

\section{Total ruang pori}

Berdasarkan hasil penelitian menunjukan bahwa pupuk kandang sapi dapat meningkatkan total ruang pori tanah $45 \%$ sebelum diberi perlakuan menjadi $69 \%$. Peningkatan total ruang pori dapat dipahami karena pupuk kandang sapi dalam tanah selain meningkatkan bahan organik tanah, juga dapat berfungsi sebagai perekat dalam pembentukan dan pemantapan agregat tanah. Air berpengaruh terhadap kondisi tanah terutama aerasi, suhu, hidrologi dan 
Julio: Pengaruh dosis puuk kandang sapi terhadap perbaikan beberapa sifat fisik, kimia dan biologi tanah pada kondisi jenuh air dan kapsitas lapang

struktur tanah. Ruang pori setiap tanah diisi sebagian oleh udara dan sebagian oleh air. Ruang yang ditempati air tidak dapat diisi oleh udara yang akan mempengaruhi oksidasi reduksi tanah (Sugito et al.,1995).

\section{Permeabilitas tanah}

Permeabilitas tanah pada kondisi jenuh air umumnya lebih tinggi dari permeabilitas pada kapasitas lapang, karena pada kondisi kapasitas lapang ruang pori yang berisi udara akan menahan gerakan air (Danahue et al. 1977). Menurut Foth (1988), ukuran pori merupakan hal yang sangat penting dengan memperhatikan aliran atau gerakan air dalam infiltrasi dan menembus (perkolasi) tanah. Berdasarkan klasifikasi permeabilitas tanah menurut Uhland dan O'neal (1967) bahwa tanah awal percobaan yang belum diberi perlakuan tergolong sangat tinggi setelah diberi perlakuan pada dosis pupuk kandang sapi dari 10-30 $\mathrm{t} \mathrm{ha}^{-1}$ dapat menurunkan menjadi agak cepat.

\section{pH Tanah}

Pengaruh interaksi antara pemakaian pupuk kandang sapi dan kadar air tanah terhadap $\mathrm{pH}$ tanah berpengaruh nyata. Pengaruh tunggal pemakaian dosis pupuk kandang sapi hanya berpengaruh nyata pada lapisan $0-20 \mathrm{~cm}$. Peningkatan $\mathrm{pH}$ tanah ini disebabkan karena bahan organik yang digunakan sudah mengalami proses dekomposis. Bahan organik yang telah terdekomposisi ini akan melepaskan moneralnya berupa kation-kation basa. Sebaliknya apabila pupuk kandang sapi yang masih mengalami proses dekomposisi, biasanya akan menyebabkan penurunan $\mathrm{pH}$ tanah, karena selama proses dekomposisi akan melepaskan asam-asam organik yang menyebabkan menurunya $\mathrm{pH}$ tanah (Suntoro, 2003; Dewi, 1996).

\section{C-Organik Tanah}

Pada kondisi jenuh air C-organik tanah umumnya meningkat, dengan meningkatnya dosis pupuk kandang sapi yang digunakan terutama pada lapisan 0$20 \mathrm{~cm}$, demikian juga pada lapisan 20-40 cm. Kondisi ini menunjukan bahwa telah terjadi pelindian dari lapsian 0-20 $\mathrm{cm}$ ke lapisan 20-40 cm. Menurut Apong dkk (2007), dengan pemberian $15 \mathrm{t} \mathrm{ha}^{-1}$ pupuk kandang sapi memberikan nilai tertinggi terhadap C-organik tanah. Menurut Aribawa dkk (2007), penambahan pupuk organik pada tanah tidak selalu meningkatkan kadar C-organik bila 
Julio: Pengaruh dosis puuk kandang sapi terhadap perbaikan beberapa sifat fisik, kimia dan biologi tanah pada kondisi jenuh air dan kapsitas lapang

dibandingkan dengan kadar C-organik tanah awal. Akan tetapi penggunaan bahan organik ke dalam tanah juga harus memperhatikan perbandingan kadar $\mathrm{C}$ terhadap unsur hara lain seperti NPK, karena apabila perbandingannya terlalu besar, bisa menyebabkan terjadinya imobilisasi (Winarso, 2005).

\section{$\mathrm{C} / \mathrm{N}$ ratio}

Interaksi dosis pupuk kandang sapi dan kadar air tanah hanya berpengaruh nyata terhadap $\mathrm{C} / \mathrm{N}$ ratio pada $45 \mathrm{hsp}$ yaitu di lapisan 0-20 cm, sedangkan pengaruh tunggal $\mathrm{C} / \mathrm{N}$ ratio hanya nyata pada 30 hsp di lapisan 20-40 cm. meningkatnya pemakaian pupuk kandang sapi, akan meningkatkan $\mathrm{C} / \mathrm{N}$ ratio terkecuali pada dosis $20 \mathrm{t} \mathrm{ha}^{-1}$. Nilai $\mathrm{C} / \mathrm{N}$ ratio ditentukan oleh faktor kematangan bahan organik pada saat pengomposan. Rasio C/N menentukan kecepatan dekomposisi bahan organik dan mempunyai hubungan dengan ketersediaan $\mathrm{N}$ antara tanaman dan mikroba. Agar tidak terjadi persaingan tersebut maka diperlukan $\mathrm{C} / \mathrm{N}$ rasio kurang lebih sama dengan 10-12 (Hakim, 1986).

\section{Nitrogen}

Nitrogen merupakan salah satu unsur hara yang sangat penting dan dapat disediakan melalui pemupukan. Tanah tempat penelitian bertekstur pasir, sehingga kondisi tanah adalah aerob. Kondisi aerob ini mengakibatkan nitrifikasi berjalan intensif sehingga $\mathrm{N}$ lebih banyak berada dalam bentuk $\mathrm{NO}_{3}{ }^{-}$ dibandingkan $\mathrm{NH}_{4}{ }^{+}$. Hal ini berkaitan dengan $\mathrm{pH}$ tanah yang tergolong netral hingga agak alkalis sehingga tidak banyak masalah bila digunakan untuk budidaya tanaman. Peningkatan kadar N-total dapat terjadi pada pupuk kandang sapi, karena nilai $\mathrm{C} / \mathrm{N}$ ratio rata-rata pupuk kandang sapi $<20$, sehingga tidak akan terjadi lagi mineralisasi dan immobilisasi. Semakin kecil nila $\mathrm{C} / \mathrm{N}$ ratio maka proses demineralisasi $\mathrm{N}$ akan berjalan dengan lebih baik.

\section{Fosfor}

Unsur P-tersedia diabsorpsi oleh akar dari dalam tanah dalam bentuk $\mathrm{H}_{2} \mathrm{PO}_{4}^{-}$dan $\mathrm{HPO}_{4}^{-2}$. Kedua bentuk fofsat tersebut ketersediaannya tergantung dari dekomposisi fosfat, umumnya meningkat dengan meningkatnya dosis pupuk kandang sapi yang diberikan. Dalam penelitian ini terjadi peningkatan $P$ tersedia. Hal ini terjadi karena 
Julio: Pengaruh dosis puuk kandang sapi terhadap perbaikan beberapa sifat fisik, kimia dan biologi tanah pada kondisi jenuh air dan kapsitas lapang

peningkatan P-tersedia tanah terjadi akibat pengaruh langsung dan pengaruh tidak langsung dari pemberian pupuk organik terhadap berbagai bentuk fosfor dalam tanah (Buckman dan Brady, 1982).

\section{Kalium}

Makin tinggi dosis pupuk kandang sapi yang diberikan menyebabkan meningkatnya kandungan kandungan $\mathrm{K}$ di dalam tanah. Hal ini disebabkan karena kandungan $\mathrm{K}$ pada pupuk kandang sapi yang tinggi. Berdasarkan data tersebut maka dapat diasumsikan bahwa pemakaian dosis pupuk kandang sapi semakin tinggi akan terus meningkatkan $\mathrm{K}$ tersedia dalam tanah, baik pada lapisan yang diberi perlakuan maupun lapisan yang tidak diberi perlakuan.

\section{Total Bakteri}

Jumlah total bakteri meningkat dengan semakin tingginya pemakaian dosis pupuk kandang sapi, baik pada lapisan $0-20 \mathrm{~cm}$ dan $20-40 \mathrm{~cm}$. Hal ini menunjukan bahwa telah terjadi pelindian bahan organik yang menjadi sumber energi bagi bakteri pada lapisan $0-20 \mathrm{~cm}$ ke lapisan 20-40 cm. Peningkatan populasi total bakteri tertinggi $86 \times 10^{4}$ terdapat pada dosis pupuk kandang sapi 30 t ha $^{-1}$ dengan kondisi kandungan jenuh air 15 hsp. Hal ini menunjukan bahwa bakteri dapat berkembang pada lapisan 0$20 \mathrm{~cm}$ pada $15 \mathrm{hsp}$. Sumber makanan merupakan faktor yang mempengaruhi peningkatan jumlah total bakteri di dalam tanah (Simanungalit dkk, 2006).

\section{SIMPULAN}

1. Pemakaian pupuk kandang sapi dapat memperbaiki sifat fisik kimia dan biologi tanah. Perbaikan terhadap sifat fisik adalah dapat menurunkan berat volume tanah, memperbesar total ruang pori sehingga dapat meningkatkan daya pegang air dalam tanah pada kondisi kapasitas lapang. Pengaruh perbaikan terhadap sifat kimia tanah terjadi pada semua variabel yang diamati. Peningkatan $\mathrm{pH}$ tanah rata-rata terjadi pad lapisan $0-20 \mathrm{~cm}$.

2. Pengaruh pemberian air dapat menyebabkan kehillangan hara yang diakibatkan pelindian dari lapisan tanah oleng diakibatkan pelindian dari lapisan tanah olah ke lapisan 20$40 \mathrm{~cm}$. Pelindian hara lebih banyak terjadi pada dosis pupuk kandang 10 $\mathrm{t} \mathrm{ha}^{-1}$ pada $15 \mathrm{hsp}$.

3. Jenis unsur hara yang paling banyak mengalami pelindian adalah unsur 
Julio: Pengaruh dosis puuk kandang sapi terhadap perbaikan beberapa sifat fisik, kimia dan biologi tanah pada kondisi jenuh air dan kapsitas lapang

hara makro yaitu $\mathrm{P}$ tersedia dan $\mathrm{K}$ tersedia, sedangkan $\mathrm{N}$ total tidak dapat diprediksikan karena sifat $\mathrm{N}$ total sangat labil. Pengaruh kehilangan $\mathrm{N}$ total dapat terjadi karena akibat pencucian mungkin juga karena penguapan.

4. Pelindian C-organik mulai terjadi pada 15, 30, dan 45 hsp, pada semua lapisan terkecuali pada 60 hsp. Pupuk kandang sapi dapat meningkatkan total bakteri di dalam tanah.

\section{Ucapan Terima Kasih}

Pada kesempatan ini penulis ingin mengucapkan terima kasih kepada semua pihak yang telah membantu dengan caranya masing-masing dalam melengkapi tulisan ini.

\section{DAFTAR PUSTAKA}

Marsono., Sigit, P. 2000. Pupuk Akar Jenis dan Aplikasinya. Jakarta: Penebar Swadaya.

Danuhue, R.L.,Miller, R.W.,Shickkluna, J.C. 1977. Soil and Introduction to Soil and Plant Growth. New Jersey: Fourth Edition Prentice Hall, Inc. Englewood Cliffs, N.J. xiii +626

Kurnia, U.A.A.,Agus, F.,Dariah, A. 2006. Sifat Fisik Tanah dan Metode Analisisnya. Bogor: Penerbit Balai Besar Litbang Sumberdaya Lahan Pertanian. Badan Penelitian dan Pengembangan Pertanian Departemen Pertanian.

Sugito, Y.,Yulia, N.,Elis, N. 1995. Sistem Pertanian Organik. Fakultas
Pertanian Universitas Brawijaya. Malang.

Suntoro, W. 2003. Peran Bahan Organik Terhadap Kesuburan Tanah dan Pengelolaannya. Sebelas Maret University Press. Surakarta.

Syukur, A. 2005. Pengaruh Pemberian Bahan Organik Terhadap Sifat-Sitat Tanah dan Pertumbuhan Calsium di Tanah Pasir Pantai. Jurnal Ilmu Tanah dan Lingkungan. Vol 5.

Apong, S.,Emma, T.S.,Olyviati, M. 2007. Pengaruh Kompos Sampah Kota dan Pupuk Kandang Sapi Terhadap Sifat kimia Tanah dan Tanaman Jagung Manis (Zea mays saccharata) Pada Fluventic Eutrudepts Asal Jatinagor Kabuapeten Sumedang. Laporan Penelitian Dasa. Universitas Padjajaran.

Aribawa, I.B.,Kartini, N.L.,Kariada, I.K. 2003. Pengaruh Beberapa Jenis Pupuk Organik dan Pupuk Urea Terhadap Sifat Tanah dan Hasil kacang Panjang di Lahan Kering Pinggiran Perkotaan Denpasar Bali. Balai Pengkajian Teknologi Pertanian. Bali.

Simanungkalit, R.D.M.,Suriadikarta, D.A.,Saraswati, R.,Setyorini, D.,Hartatik, W. 2006. Pupuk Organik dan Hayati. Balai Besar Litbang Sumberdaya Lahan Pertanian Badan Penelitian dan Pengembangan Pertanian. Jakarta. 